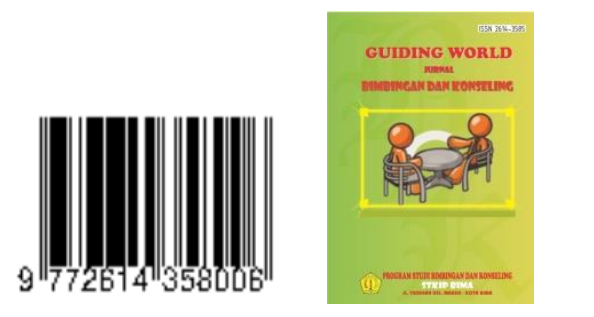

\title{
Pengaruh Bimbingan Kelompok Terhadap Peningkatan Sikap Percaya Diri Peserta Didik Dari Keluarga Kurang Harmonis
}

\author{
Nurhayati, Faijin, Nur Syariful Amin, Amiruddin \\ Prodi Studi Bimbingan \& Konseling Sekolah Tinggi Keguruan dan Ilmu Pendidikan (STKIP) \\ Bima \\ Email: sophynurhayati@yahoo.co.id
}

\begin{abstract}
Abstrak: Kepercayaan diri penting dimiliki oleh setiap orang terutama usia remaja, karena masa remaja sedang dalam proses perkembangan dan masa yang rentan maka dibutuhkan peran berbagai pihak untuk membantu ketuntasan masa ini. Keluarga sebagai fondasi awal pendidik dan pembentuk remaja maka peran keluarga sangat vital, oleh karena itu, penting keluarga menjalin komunikasi yang terbuka, hangat dan kooperatif yang mendukung anak remaja berkembang positif sehingga remaja tumbuh dan berkembang rasa percaya dirinya. Kondisi yang terjadi di lapangan ditemuka banyak kasus remaja yang terlibat dalam hal negatif seperti pengguna NAPZA disebabkan oleh kendali orang lain, remaja mudah putus asa, remaja menarik diri dari pergaulan sosial, bahkan remaja yang bunuh diri karena merasa tidak berguna. Tujuan penelitian ini untuk melihat pengaruh bimbingan kelompok terhadap kepercayaan diri peserta didik dari kelurga kurang harmonis. Penelitian ini menggunakan pendekatan kuantitatif jenis true experiment kelompok kontrol dan kelompok eksperimen. Penelitian ini menggunakan instrumen pedoman observasi, tes dan dukumentasi. Kemudian data di analisis menggunakan statistik non parametrik uji tanda (sign test). Hasil posttest untuk kelompok eksperimen diperoleh nilai sebesar 66\% dengan tujuh kali treatmen menggunakan bimbingan kelompok. Pada kelompok kontrol nilai rata-rata postestnya adalah $50 \%$ tanpa di beri perlakuan dan perbedaan perlakuan antara kedua kelompok adalah 16\%.Data hasil penelitian menunjukan bahwa $t_{\text {hitung }} 32,233>t_{\text {tabel }}=3,182$, maka $H_{o}$ di tolak dan $\mathrm{H}_{a}$ di terima dengan nilai meannya adalah 24,250.

Berdasarkan data tersebut di atas, disimpulkan bahwa bimbingan kelompok berpengaruh untuk meningkatkan sikap percaya diri peserta didik dari keluarga kurang harmonis.
\end{abstract}

Kata Kunci: Bimbingan Kelompok, Percaya Diri, Keluarga Kurang Harmonis.

\section{PENDAHULUAN}

Keluarga merupakan wadah pendidikan yang memiliki pengaruh cukup signifikan bagi perkembangan dan kedewasaan anak. Pendidikan dalam keluarga dimulai sejak anak tersebut masih dalam kandungan hingga akhir hayatnya, baik pendidikan moral, etika, keterampilan dll. Orangtua hendaknya memberi dukungan positif dan menghargai potensi yang dimiliki oleh setiap anak, serta memelihara dan memberikan rangsangan yang positif guna untuk menunjang kemajuan anak. Pernyataan ini secara jelas mengiformasikan bahwa para Orangtua hendaknya memberi dukungan positif bagi perkembangan anak mereka. Oleh karena itu Orangtua juga diharapkan mampu memberikan bimbingan dan pendidikan yang 


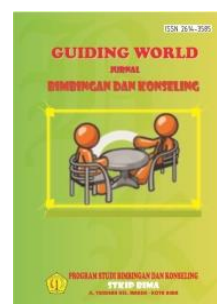

positif dilingkungan tempat anak itu tumbuh dan berkembang. Keluarga juga merupakan tempat pertama kali seorang anak belajar selama hidupnya. Seorang individu membutuhkan kedekatan dan hubungan yang hangat dengan orang tuanya. Kedekatan anak dengan orang tua itu akan mempengaruhi antusias belajar anak (Hurlock 1999).

Kondisi keluarga atau orangtua yang tidak baik juga dapat mempengaruhi motivasi maupun tingkat antusias belajar peserta didik, karena orang tua cenderung membiarkan atau tidak memberikan perhatian kepada anaknya sehingga motivasi belajarnya akan menurun. Individu yang memiliki kondisi keluarga yang harmonis akan mendapatkan pengarahan dan perhatian dari orangtua sehingga anakpun tumbuh dan berkembang dengan sikap percaya diri. Keluarga harmonis merupakan keluarga yang penuh dengan ketenangan, ketentraman, kasih sayang dan saling membantu serta bekerja sama (Ali Qaimi,2002).

Kepercayaan diri membantu para remaja dalam penyesuaian sosial. Burns dalam (Walgito, 1993) menjelaskan kepercayaan diri adalah salah satu aspek kepribadian yang terbentuk melalui interaksi individu dengan lingkungannya. Kepercayaan diri berkaitan dengan evaluasi tingkah laku pribadi (Lanney, 1977), dengan prestasi dan kemampuan diri serta melibatkan aspek perasaan (Sarason, Bandura, 1993). Hal ini sangat di pengaruhi oleh bagaimana cara mendidik orang tua di rumah dan guru di sekolah.

Kegiatan Bimbingan Kelompok menggunakan dinamika kelompok untuk mendorong para anggota untuk mencapai tujuan. Dinamika kelompok menjadi energi kekuatan penggerak yang aktif dan efektif sehingga para anggota kelompok bekerjasama selamat bimbingan berlangsung. Menurut Gibson (2011) bimbingan kelompok mengacu kepada aktivitas- aktivitas kelompok yang berfokus pada penyediaan informasi atau pengalaman melalui aktivitas kelompok yang terencana dan terorganisasi/

\section{LANDASAN TEORI}

Tahap-Tahap Bimbingan Kelompok

1. Tahap persiapan

a. Menyusun RPL

b. Menyiapkan jadwal perencanaan pelaksanaan kegiatan kelompok.

c. Pemimpin kelompok/guru BK mengajukan surat permohonan penggunaan laboratorium.

d. Pemimpin kelompok/guru BK menyiapkan dan mengatur fasilitas (ruangan) pelaksanaan kegiatan. Pengelolaan tempat pelaksanaan kegiatan penting diperhatikan agar anggota kelompok merasa nyaman dan bertahan selama kegiatan berlangsung. Hal-hal yang dipersiapkan:

e. Pemimpin kelompok/guru BK mengatur tempat/kelas pelaksanaan kegiatan agar nyaman.

1) Bila menggunakan kursi dan meja, maka diatur sedemikan rupa dengan pencahayaan dan sirkulasi udara yang cukup.

2) Jika duduk dilantai (menggunakan karpet) usahakan jarak posisi duduk annggota tidak terlalu berjauhan, karena semakin dekat posisi duduknya (tidak berjarak) memungkinkan emosi peserta didik saling mempengaruhi.

f. Pemimpin kelompok/guru BK menyeleksi anggota kelompok.

g. Pemimpin kelompok/guru BK menyiapkan dan mengkoordinir anggota kelompok yang mengikuti kegiatan kelompok. Ingat, keanggota dalam konseling kelompok adalah sukarela, dan jumlahnya sampai 18 orang. 


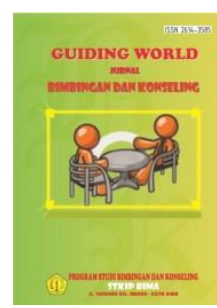

2. Tahap pelaksanaan

a. Tahap Awal; Tahap Pembentukan Kelompok (Waktunya 15 Menit)

1) Pemimpin kelompok menyambut anggota kelompok dengan hangat dan terbuka sambil mengucapkan terima kasih.

2) Berdoa bersama.

3) Pemimpin kelompok memperkenalkan diri dan menjelaskan tugas dan perannya selama kegiatan kelompok.

4) Pemimpin kelompok menjelaskan pengertian dan tujuan kegiatan kelompok.

5) Pemimpin kelompok meminta anggota kelompok menuliskan harapan-harapan yang ingin dicapai dalam kegiatan tersebut, kemudian membacanya di depan anggota lain.

6) Pemimpin kelompok membuat kontrak aturan dan tata tertib kegiatan yang harus dipatuhi oleh anggota kelompok.

7) Pemimpin kelompok menjelaskan hak-hak dan kewajiban tiap anggota kelompok

8) Pemimpin kelompok menjelaskan tugas leader selama kegiatan kelompok.

9) Pemimpin kelompok menjelaskan tentang teknik konseling yang digunakan dalam kegiatan.

10) Pemimpin kelompok menjelaskan asas-asas kegiatan kelompok: Asas kerahasiaan, asas keterbukaan, tutwuri handayani, kegiatan, dan kenormatifan

11) Pemimpin kelompok meminta anggota kelompok untuk saling memperkenalkan diri.

b. Tahap Peralihan

1) Menjelaskan kembali tentang kegiatan kelompok.

2) Membahas suasana yang terjadi.

3) Pemimpin kelompok meningkatkan keikutsertaan anggota kelompok.

4) Pemimpin kelompok menanyakan kesiapan anggota kelompok untuk melanjutkan ke tahap berikut.

5) Mengenali bila seluruh/sebagian anggota kelompok belum siap melanjutkan ke tahap kerja.

6) Pemimpin kelompok member contoh masalah yang dibahas dalam kegiatan kelompok.

7) Bila semua anggota kelompok sudah siap maka kegiatan dilanjutkan.

c. Tahap Kerja

1) Pemimpin kelompok mendorong anggota untuk menceritakan masalahnya

2) Menyepakati masalah yang akan dibahas terlebih dahulu

3) Pembahasan masalah. Setiap anggota kelompok membahas masalahnyya secara mendalam

d. Tahap Pengakhiran

1) Pemimpin kelompok mengingatkan bahwa kegiatan kelompok akan segera berakhir

2) Pemimpin kelompok dan anggota kelompok menyampaikan pesan dan kesan selama kegiatan kelompok

3) Membuat simpulan

4) Membahas kegiatan lanjutan

e. Tahap evaluasi 


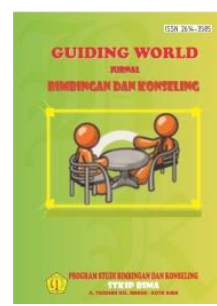

Konselor realita menggunakan pertanyaan-pertanyaan dibawah ini dan meminta anggota kelompok menjawabnya untuk membantu mengevaluasi dirinya sendiri

1) Apakah yang sedang anda lakukan membantu atau menyusahkan anda?

2) Apakah yang sedang anda lakukan adalah apa yang ingin anda lakukan?

3) Apakah tingkahlaku anda membantu anda?

4) Apakah ada kesesuaian antara apa yang sedang anda lakukan dan apa yang anda yakini?

5) Apakah yang sedang anda lakukan melanggar hukum?

6) Apakah yang anda inginkan masuk akal dan mungkin dicapai?

7) Apakah keinginan tersebut membantu anda untuk bersikap dengan cara itu?

8) Bagaimana komitmen anda dalam proses terapi dan untuk mengubah kehidupan anda?

9) Setelah anda menguji apa yang anda inginkan dengan cermat, apakah hal tersebut benar-benar apa yang anda inginkan dan bukan keinginan orang lain?.

Kemudian konselor meminta masing-masing anggota kelompok mengevaluasi masingmasing komponen dari keseluruhan tingkahlaku mereka dan membantu mereka untuk membuat keputusan yang efektif

Sikap Percaya Diri

Sikap percaya diri sesuatu yang sangat penting yang dimilki oleh seseorang untuk menentukan kebahagian hidup. Seseorang yang tidak memiliki sikap percaya diri akan tumbuh menjadi individu yang tidak kreatif dan tidak produktif. Percaya diri dapat di artikan juga sebagai perasaan yang mendalam pada batin seseorang,bahwa ia mampu berbuat sesuatu yang bermanfaat untuk diri, keluarga, masyarakat, agama dan negara yang memotivasi dirinya untuk tetap optimis, kreatif dan dinamis (Muzakir, 2006). Adapun indikator dari sikap percaya diri adalah selalu optimis,menghargai diri sendiri, inovatif, kreatif,berani mencoba dan menjalin hubungan baik dengan orang-orang di sekitarnya.

Ciri-ciri Individu Yang Percaya Diri tampak pada: (1) cara membaca dan menggunakan bahasa tubuh, bertindak penuh percaya diri saat merasa lemah, cara menyikapi kegagalan dan merayakan kemenangan, cara memvisualisasikan keberhasilan, cara menginspirasi dan membangkitkan kepercayaan diri dalam diri orang lain.

Aspek-Aspek Sikap Percaya Diri

Modal utama dalam membangun sikap percaya diri adalah kemauan,ketekunan dan selalu berusaha tanamkan pada diri bahwa "aku ingin lebih percaya diri" apabilah telah yakin, mulailah dengan menerapkan aspek-aspek atau kiat-kiat antar lain: memootivasi diri dan sikap optimis; Motivasi adalah dorongan yang timbul pada diri seseorang secara sadar atau tidak sadar untuk melakukan suatu tindakan dengan tujuan tertentu. Motivasi bisa datang dari diri sendiri maupun dari luar diri (orang lain, lingkungan). Sedangkan sikap optimis sangat di perlukan dalam menghadapi suatu permasalahn, karena dengan sikap optimis seseorang dapat mengatasi persoalan hidupnya dengan lebih baik. Untuk memiliki sikap optimisme seseorang haruslah memiliki kepercayaan pada diri sendiri. Zakiah Darajat (1990:25) dalam buku kesehatan mental menyatakan bahwa sikap kepercayaan diri akan menyebabkan seseorang optimis dalam hidupnya. 


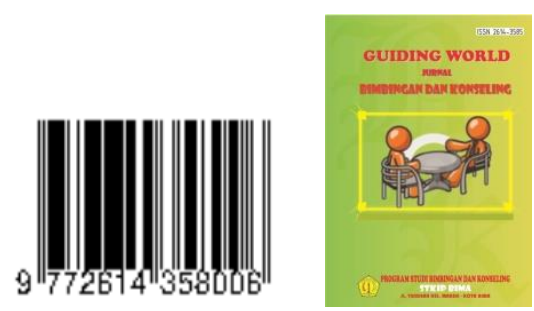

DOI: 1033627

Volume 03, Nomor 02

November 2020

E-ISSN:2614-3585

\section{METODE PENELITIAN}

Penelitian ini menggunakan pendekatan kuantitatif jenis true eksperiment dengan menggunakan kelompok eksperimen dan kelompok kontrol. Data kuantitatif diperoleh dari hasil pretest (tes awal) dan posttest (tes akhir), yang selanjutnya dianalisis secara kuantitatif.

Desain penelitian yang digunakan adalah Subjek random pretest-posttest grup. Dalam desain ini, sebelum perlakuan diberikan terlebih dahulu sampel diberikan pretest (tes awal) dan pada akhiri pemberian perlakuan sampel diberikan posttest (tes akhir). Desain ini digunakan untuk mengetahui seberapa besar Pengaruh Bimbingan Kelompok Terhadap Peningkatan Sikap Percaya Diri Peserta Didik dari Keluarga Kurang Harmonis

Berikut merupakan tabel desain penelitian Subjek random desain pretest-posttest grup. Adapun desain terlihat pada Gambar 1.1. Desain Penelitian

\begin{tabular}{|l|l|c|l|c|}
\hline & Grup & Pretes & $\begin{array}{l}\text { Variabel } \\
\text { Terkait }\end{array}$ & Postes \\
\hline $\mathrm{R}$ & Eksperimen & $Y_{1}$ & $\mathrm{X}$ & $Y_{2}$ \\
\hline $\mathrm{R}$ & Kontrol & $Y_{1}$ & - & $Y_{2}$ \\
\hline
\end{tabular}

Keterangan:

R: Random (sampel yang di acak)

$Y_{1}$ : tes awal (pretes) sebelum perlakuan di berikan

$Y_{2}$ : tes akhir (posttest) setelah perlakuan di berikan

X: Perlakuan terhadap kelompok eksperimen

\section{Analisis Data}

Data yang di peroleh dalam penelitian ini akan di analisa dengan analisa statistik dengan menggunaka T Standar Test (t),dengan rumus sebagai berikut:

$$
t=\frac{M d}{\sqrt{\frac{\sum x^{2} d}{N(N-1)}}}
$$

Keterangan :

Md = Mean dari perbedaan pre test dengan posttest

$\mathrm{Xd}=$ Devisiasi masin-masing subjek $(\mathrm{d}-\mathrm{Md})$

$\sum x^{2} \mathrm{~d}=$ Jumlah kuadrat deviasi

$\mathrm{N} \quad=$ Subjek pada sampel

d.d = ditentukan dengan $\mathrm{N}-1$

(Suharsimi:1998)

\section{HASIL PENELITIAN}

\section{Data Hasil Kelas Eksperimen Untuk Pretest dan Posttest}

Hasil dari pretest dan postest yang dilakukakan pada kelas eksperimen sebelum diberikan perlakuan (Bimbingan Kelompok) dan sesudah diberikan perlakuan (Bimbingan Kelompok), peserta didik yang berjumlah 4 orang memperoleh nilai minimum 35 dan nilai maksimum 50 untuk pretest dengan nilai rata-rata 42,5. Sedangkan untuk posttest setelah diberi perlakuan (Bimbingan Kelompok) selama 7 kali pertemuan memperoleh nilai minimum 


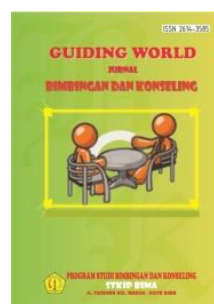

DOI: 1033627

Volume 03, Nomor 02

November 2020

E-ISSN:2614-3585

60 dan maksimum 75 dengan nilai rata-rata 66. Hal ini dapat dilihat pada tabel 1.2 dan tabel 1.3 dibawah ini.

Tabel 1.2 Hasil Untuk Pretest dan Posttest Kelompok Eksperimen.

\begin{tabular}{|c|c|c|c|c|c|c|c|c|c|}
\hline \multirow{2}{*}{ No } & \multirow{2}{*}{ Subjek } & \multicolumn{1}{|c|}{$\begin{array}{c}\text { Nilai } \\
\text { Pretes }\end{array}$} & \multicolumn{7}{|c|}{ Nilai Postes } \\
\cline { 3 - 11 } & & $\begin{array}{c}\text { Pertemuan } \\
1\end{array}$ & 2 & 3 & 4 & 5 & 6 & 7 & 8 \\
\hline 1. & $\mathrm{Ra}$ & 45 & 46 & 50 & 53 & 54 & 59 & 62 & 67 \\
\hline 2. & $\mathrm{Li}$ & 50 & 52 & 55 & 57 & 60 & 62 & 65 & 75 \\
\hline 3. & $\mathrm{Nm}$ & 35 & 37 & 40 & 44 & 47 & 52 & 55 & 60 \\
\hline 4. & $\mathrm{Sy}$ & 40 & 44 & 46 & 50 & 53 & 55 & 60 & 65 \\
\hline Jumlah & & 170 & 179 & 191 & 204 & 214 & 228 & 242 & 267 \\
\hline$\sum$ & & 42.5 & 44. & 47. & 51 & 53. & 57 & 60 & 66 \\
& & & 8 & 8 & & 5 & & & \\
\hline
\end{tabular}

Tabel 1.3 Penggabungan Hasil Pretest dan Post Test Pada Kelompok Eksperimen

\begin{tabular}{|c|l|c|c|}
\hline \multirow{2}{*}{ No } & \multirow{2}{*}{ Deskriptor } & \multicolumn{2}{|c|}{ Eksperimen } \\
\cline { 3 - 4 } & & Pretest & Postest \\
\hline 1. & Jumlah Peserta didik & 4 & 4 \\
\hline 2. & Nilai Terendah & 35 & 60 \\
\hline 3. & Nilai Tertinggi & 50 & 75 \\
\hline 4. & Rata-rata & 42.5 & 66 \\
\hline
\end{tabular}

Berdasarkan tabel 1.2. dan 1.3 di atas menunjukan bahwa hasil untuk kelas eksperimen ketika diberi pretest (sebelum diberi perlakuan) lebih rendah di bandingkan hasil posttest (setelah di beri perlakuan) berupa bimbingan kelompok hasilnya lebih tinggi, hal ini membuktikan bahwa metode bimbingan kelompok sangat berpengaruh untuk mengetahui seberapa besar sikap percaya diri yang di miliki oleh setiap peserta didik yang tergabung dalam kelas eksperimen di SMP Negeri 3 Kota Bima.

\section{Data Hasil Pretest dan Posttest Kelompok Kontrol}

Hasil pretest dan posttest yang dilakukan pada kelompok kontrol tanpa diberi perlakuan (bimbingan kelompok), peserta didik hanya memperoleh nilai minimum 40 dan nilai maksimumnya 55 untuk pretest dengan nilai rata-rata 45,5. Sedangkan peserta didik memperoleh nilai minimum 45 dan nilai maksimumnya 55 untuk postest dengan nilai ratarata 50, seperti pada tabel 1.3 dan tabel 1.3 dibawah:

1.3. Tabel Hasil Pretest dan Postest Untuk Kelompok Kontrol

\begin{tabular}{|l|c|c|c|}
\hline \multirow{2}{*}{ NO } & & \multicolumn{2}{|c|}{ Kelompok eksperimen } \\
\cline { 3 - 4 } & NAMA & Pretest & Postest \\
\hline 1. & $\mathrm{Ra}$ & 50 & 55 \\
\hline 2. & $\mathrm{Li}$ & 47 & 50 \\
\hline
\end{tabular}




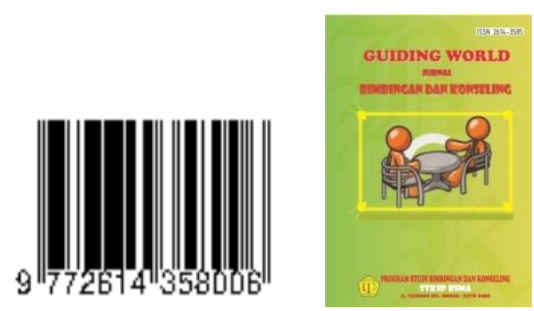

DOI: 1033627

\begin{tabular}{|l|c|c|c|}
\hline 3. & Nm & 40 & 45 \\
\hline 4. & Sy & 45 & 50 \\
\hline Jumlah & & 182 & 200 \\
\hline$\sum$ & Jumlah nilai & 45.5 & 50 \\
\cline { 2 - 4 } & Jumlah Sample & & \\
\hline
\end{tabular}

1.4.Tabel hasil untuk pretest dan postest untuk kelompok kontrol

\begin{tabular}{|c|l|c|c|}
\hline \multirow{2}{*}{ No } & \multirow{2}{*}{ Deskriptor } & Pretest & \multicolumn{2}{|c|}{ Kontrol } \\
\cline { 3 - 4 } & & 4 & 4 \\
\hline 1. & $\begin{array}{l}\text { Jumlah } \\
\text { Peserta didik }\end{array}$ & 40 & 45 \\
\hline 2. & $\begin{array}{l}\text { Nilai } \\
\text { Terendah }\end{array}$ & 50 & 55 \\
\hline 3. & Nilai Tertinggi & 45.5 & 50 \\
\hline 4. & Rata-rata & \multicolumn{2}{c|}{} \\
\hline
\end{tabular}

Pada kedua tabel di atas,terlihat bahwa nilai hasil belajar peserta didik pada kelompok kontrol untuk pretest dan posttest sangat rendah dan menurun karena tidak ada perlakuan yang di berikan berupa bimbingan kelompok.

Hasil Uji T ( $\left.\mathbf{T}_{\text {test}}\right)$

Uji t-test di gunakan untuk mengetahui seberapa besar perbedaan kemampuan antara setiap anak pada kelompok eksperimen setelah diberikan perlakuan berupa bimbingan kelompok,dengan menggunakan SPSS 21 dengan perbandingan setiap anak pada kelompok eksperimen yang tidak di berikan perlakuan berupa bimbingan kelompok. Untuk melihat perbedaannya bisa di lihat pada tabel 1.5. di bawah ini:

\section{Paired Samples Test}

\begin{tabular}{|c|c|c|c|c|c|c|c|c|}
\hline & \multicolumn{5}{|c|}{ Paired Differences } & \multirow{3}{*}{$\mathrm{T}$} & \multirow{3}{*}{ Df } & \multirow{3}{*}{$\begin{array}{l}\text { Sig. (2. } \\
\text { tailed) }\end{array}$} \\
\hline & \multirow[t]{2}{*}{ Mean } & \multirow[t]{2}{*}{$\begin{array}{c}\text { Std. } \\
\text { Deviation }\end{array}$} & \multirow[t]{2}{*}{$\begin{array}{l}\text { Std. Error } \\
\text { Mean }\end{array}$} & \multicolumn{2}{|c|}{$\begin{array}{c}\text { 95\% Confidence } \\
\text { Interval of the } \\
\text { Difference }\end{array}$} & & & \\
\hline & & & & Lower & Upper & & & \\
\hline $\begin{array}{ll} & \text { Eksperim } \\
\text { Pair 1 } & \begin{array}{l}\text { en- } \\
\text { Kontrol }\end{array} \\
\end{array}$ & 24,250 & 1,500 & ,750 & $-26,637$ & 21,863 & 32,333 & 3 & 0,001 \\
\hline
\end{tabular}

Nilai perbedaan antara kelompok eksperimen yang di beri perlakuan dengan kelompok kontrol yang tidak diberi perlakuan adalah adalah $: t_{\text {tabel }}$ dengan taraf signifikan adalah 0,0027.Hasil dari signifikan (2 tailed) dengan nilai value uji t paired adalah 0,001.Sebab nilai $\mathrm{P}$ value $>0,05$ (dari 95\% kepercayaan) dan df (derajat kebebasan) : $\mathrm{N}$ 1.Jadi nilai $t_{\text {hitung }}=32,233$ dan nilai $\mathrm{Df}$ adalah $=3,182$. Karena $t_{\text {hitung }}$ lebih besar dari $t_{\text {tabel }}$ atau $t_{\text {hitung }}=32,233>t_{\text {tabel }}=3,182$, maka $H_{o}$ di tolak dan $H_{a}$ di terima dengan nilai mean adalah 24,250 . Dengan demikian dapat di simpulkan adanya peningkatan yang positif untuk mengetahui seberapa besar pengaruh bimbingan kelompok untuk sikap percaya diri 


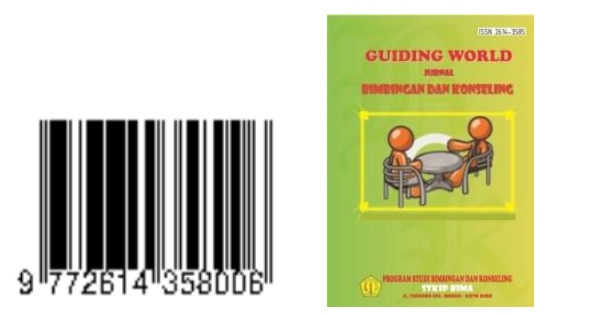

antara kelompok eksperimen yang di beri perlakuan berupa bimbingan kelompok dengan kelompok kontrol yang tidak di berikan perlakuan di SMP N 3 Kota Bima.

\section{Kesimpulan}

Berdasarkan hasil analisis data dan pembahasan penelitian ini, pada kelompok eksperimen dan kelompok kontrol diperoleh bahwa ada perbedaan yang signifikan antara kelompok eksperimen yang diberikan perlakuan berupa bimbingan kelompok dengan kelompok kontrol tanpa diberikan perlakuan. Hal ini ditunjukan dengan nilai rata-rata hasil pretest dan posttest pada kedua kelompok tersebut yaitu kelompok eksperimen $66 \%$ lebih besar dari kelompok kontrol yaitu 50\%, maka dapat disimpulkan bahwa "bimbingan kelompok berpengaruh untuk meningkatkan sikap percaya diri peserta didik dari keluarga kurang harmonis.

\section{Saran}

Berdasarkan hasil yang diperoleh, maka dapat diajukan beberapa saran sebagai berikut:

1. Bagi konselor agar lebih meningkatkan pelayanan bimbingan dan konseling dalam membantu peserta didik yang kurang memiliki sikap percaya diri, sehingga peserta didik mampu mengembangkan potensi dirinya dan merancanakan masa depan yang lebih baik.

2. Untuk peserta didik diharapkan untuk berkonsultasi dan memanfaatkan kegiatan layanan Bimbingan dan Konseling untuk membantu perkembangannya

3. Kepada peneliti selanjutnya agar bisa meneliti lebih lanjut dan mendalam tentang masalahkepercayaan diri peserta didik dari keluarga kurang harmonis untuk membantu dalam menangani permasalahan peserta didik.

4. Pada orang tua diharapkan untuk menjaga komunikasi dan keharmonisan keluarga hubungannya agar anak-anak tumbuh dan berkembang secara wajar dan percaya diri.

\section{DAFTAR PUSTAKA}

AfiAanti, A. 1996. Harga diri. Bulan bitang. Jakarta.

Berg, R., Landreth, G, L., \& Fall, K, A. 2006. Group Counseling Concepts and Procedures, Fourth Edition. New York: Brunner-Routledge

Brown, N.W. 1994. Group Counseling For Elementary and Middle School Children. Connecticut London: Praeger

Corey, G. 2012. Theory \& Practice Of Group Counseling, Eighth Edition. Canada: Cengage Learning.

Creswell, J. 2012. Educational Reaserch planning, Conducting and Evaluating Quantitative and Qualitative Research. New York: University Of Nebraska Lincoln Pearson.

Erford, B.T. 2010. Group Work in the Schools. Boston: Pearson Education, Inc

Gibson, R., L. Dan Mitchell, M., H. 2011. Bimbingan dan Konseling. Yogyakarta: Pustaka Pelajar.

I.B. Netra.1974.Statistik Inferensial.Surabaya: Usaha Nasional.

Mulyani. 2003 Konseling Keluarga. Yogyakarta: Universitas Negeri Yogyakarta

Santoso, S. 2001. Buku Latihan SPSS Statistik Non Parametrik. Jakarta: Gramedia.

Sonstegard, M., Bitter, J, R., \& Pelonis, P. 2004. Adlerian Group Counseling and Therapy Step-b. 